\title{
Lesley Gill. (2016). A Century of Violence in a Red City: Popular Struggle, Counterinsurgency, and Human Rights in Colombia. Durham: Duke University Press, 304 páginas $^{1}$
}

Por Mauricio Archila Neira ${ }^{2}$

$\mathrm{B}$ arrancabermeja es una de las ciudades más estudiadas en Colombia, no solo por ser el principal centro petrolero del país, sino por contar con una tradición política contestataria que algunos designamos como radical. Pero este libro de la antropóloga norteamericana Lesley Gill ofrece varias novedades. Aunque ya ha habido extranjeros que han estudiado a Barranca — como coloquialmente se le conoce-, lo han hecho desde una perspectiva casi apologética de la explotación petrolera y más recientemente de forma crítica, desde la defensa de los derechos humanos. Esta es una perspectiva que considera la profesora de la Universidad de Vanderbil, Lesley Gill, pero ella va más allá, incluso polemiza con el enfoque de derechos humanos, y en eso radica la novedad del texto reseñado. En efecto, su clave de análisis es la categoría clase y desde allí intenta leer en forma muy coherente el efecto del capitalismo y la violencia - los hermanos gemelos, como los

Una versión muy breve de esta reseña fue publicada por la Revista Europea de Estudios Latinoamericanos y del Caribe (ERLAC, por las siglas en inglés), No. 103 de 2017.

2 Profesor titular de la Universidad Nacional de Colombia e investigador en Cinep/PPP. 
llama - en el hacerse y deshacerse de la clase trabajadora barranqueña. Algo que había analizado para Bolivia e inclusive para su mismo país. Ya volveremos sobre esta discutible hipótesis.

La otra novedad, tal vez no tan polémica como la anterior, es metodológica: el uso de testimonios directos por el trabajo de campo que valientemente realizó en esa ciudad desde 2004, cuando fue invitada por los trabajadores de Coca Cola a acompañarlos en la lucha por la defensa de la vida. Y decimos valientemente no solo por el calor sofocante que se respira en este puerto sobre el río Magdalena todo el año, sino, sobre todo, porque la ciudad desde 1998 sufrió una brutal incursión de paramilitares que rechazaban cualquier pensamiento crítico, así proviniera de una extranjera. Por tanto, su vida estuvo en juego -así no lo confiese mucho a lo largo de las trescientas páginas de su libro-. En ese sentido, aunque la autora no reflexione mucho sobre el método de investigación - lo cual es una lástima pues hubiera dado muchas claves de comprensión de su texto-, sin duda se trata de una etnología comprometida con la suerte de la gente a la que acompañó por casi diez años de viajes intermitentes a la zona. Así lo reconoce brevemente en la página final de sus conclusiones. En ese orden de ideas, la novedad empírica está en ese trabajo de campo y en los testimonios conseguidos con paciencia y solidaridad, que son hábilmente entrelazados con la lectura de fuentes secundarias y reflexiones teóricas a lo largo del texto.

El libro en cuestión tiene siete capítulos más la introducción. En esta la autora plantea sus motivaciones para hacer la investigación y cómo se dio el acompañamiento a los empleados de Coca Cola y, en general, a los trabajadores de Barrancabermeja, a renglón seguido expone su enfoque teórico, que, como hemos dicho, es de clase. Este enfoque es una lectura marxista de la acumulación de capital por desposesión, en la que se articula la flexibilización laboral neoliberal con la violencia estatal y paramilitar. También señala una comprensión muy amplia de la clase obrera, que incluye trabajadores rurales y urbanos a veces considerados como campesinos o capas medias. Y, por último, indica que 
su visión del Estado no remite solo a la materialidad institucional, como si fuera una "cosa", sino que lo ve como un conjunto de relaciones y alianzas de poder.

Luego, Lesley Gill entra en materia para lo cual sigue una línea cronológica en los tres primeros capítulos y después hace un análisis sincrónico más detallado del fenómeno paramilitar en los cuatro siguientes. Así, en el primer capítulo toca la llegada en los años veinte del siglo pasado de la subsidiaria de la Exxon, la Tropical Oil Company, y la creación de un enclave petrolero en la mitad del país - lo que desde los años cincuenta se llamará Magdalena Medio-. Dicho enclave alimentó la formación de una clase obrera antiimperialista y solidaria. En la siguiente sección, la autora aborda la segunda mitad del siglo veinte para destacar como esa clase trabajadora acompañó a los pobladores y campesinos en sus luchas reivindicativas, especialmente por servicios públicos domiciliarios y en particular por el agua, a través de paros y luchas "cívicas" en los años sesenta y setenta. En el tercer capítulo hace el recuento de la aterradora llegada de los paramilitares en los años ochenta, especialmente desde la masacre del 16 de mayo de 1998, que desplaza a las guerrillas implantadas en los barrios populares con el auge de las luchas cívicas.

A partir de ese momento, la autora orienta los siguientes capítulos al análisis de esa violencia y del nuevo orden paramilitar que se genera en Barranca y en el Magdalena Medio. De esta forma, en el capítulo cuatro estudia la reestructuración económica en Coca Cola, tanto en el ámbito global como en el nacional y el local, y destaca la alianza entre empresarios y paramilitares con un mismo fin: debilitar el sindicalismo para favorecer la acumulación capitalista por desposesión del trabajo y hasta de la vida. En el siguiente apartado reflexiona sobre el significado del orden paramilitar en términos de la precaria construcción del Estado en Colombia. Allí, la autora afirma que los paramilitares no pretendían sustituir al Estado, sino más bien usarlo a su favor, aunque poco después, en forma contradictoria, usa la expresión "para-Estado" para referirse a su dominio. A continuación aborda el otro lado de esa 
dominación, la resistencia popular, en este caso a través del lenguaje de los derechos humanos. Aquí la autora hace una dura crítica a ese lenguaje que, surgido en la tradición liberal, individualiza a los colectivos, los pone a pelear en términos legales, lo que los despolitiza mientras los deja sin bases sociales, pues esta labor no las requiere. Claro que ella acota inmediatamente que también es un lenguaje que puede dar cabida a viejas y nuevas reivindicaciones, como es el caso de los derechos laborales y ahora de género y de diversidad sexual. Este es uno de los apartes en donde se hacen evidentes las consecuencias teóricas y políticas de su enfoque de clase.

Finalmente, Lesley Gill termina esta gran segunda parte del libro con un breve análisis de lo que ocurre en el inicio de este decenio, que se puede resumir como la continuación de la guerra por otros medios a pesar de la desmovilización de los grupos paramilitares, que en realidad, bajo otros nombres, siguen sembrando terror en el Magdalena Medio y en otras regiones conflictivas del país. Por supuesto, el mensaje de estas secciones finales es muy pesimista frente al futuro no solo de Barranca, sino del país. Sin embargo, intenta matizar en algo las conclusiones diciendo que el proceso de "deshacer" la clase trabajadora no está aún completo y que de esas cenizas surgirán alternativas de cambio social. Así, termina redondeando un argumento coherentemente desarrollado a lo largo de trescientas páginas sobre el impacto del capitalismo violento en una "ciudad roja". Pero en realidad es una lectura no solo pesimista, sino un poco plana de la historia de Barranca y, desde allí, de la historia de Colombia.

Me explico. Cuando uno termina de leer el libro de Lesley Gill tiene la impresión de que la historia de Barranca fue la de un cambio extremo de una cultura radical obrera y ciudadana, que predominó entre los años veinte y los ochenta, a una cultura individualista, fragmentada y egoísta, implantada de los años noventa para acá. Es lo que la autora, en términos thompsonianos, refiere como el hacerse y deshacerse making and unmaking - de la clase trabajadora. Personalmente tengo 
una imagen distinta de los obreros y pobladores barranqueños por el conocimiento que tuve de ellos desde los años ochenta, como lo plasmé en varios trabajos en los que me apoyaba en sus testimonios, textos que la autora juiciosamente cita. En pocas palabras, ni la clase obrera barranquera estaba tan "hecha" en los años ochenta, ni el terror paramilitar la destruyó tanto como la autora sugiere. Creo que la historia no es de blanco o negro, sino de muchos matices de grises, unos más oscuros y otros más claros.

Es cierto que el capitalismo históricamente ha estado acompañado de violencia - ya lo decía Marx al hablar de la acumulación originaria- y que el neoliberalismo en Colombia, y en especial en el Magdalena Medio, se articula con el terror paramilitar para destruir el sindicalismo, como lo hemos señalado en un libro que la autora infortunadamente no conoció,,$^{3^{*}}$ pero no deja de ser un poco lineal la forma de exposición de ella, incluso en el orden de los capítulos. Tal vez el haber llegado a Barranca en 2004 en pleno auge del paramilitarismo la hace idealizar un pasado narrado por sus entrevistados, un pasado que no era tan solidario y radical como nostálgicamente lo recuerdan, en contraste con un presente que se percibe aterrador, como seguramente lo trasmitieron las víctimas de esa violencia y ella misma lo vivió en su trabajo de campo. Yo creo que hay muchas formas de resistencia subalterna en los barrios populares que no se analizan en el libro. Por ejemplo, las formas de economía popular en iniciativas como las mujeres de "Merquemos juntos”, muchas de las actividades de las Juntas de Acción Comunal - como se alcanza a vislumbrar en el testimonio de Leonardo Páez en el capítulo cinco- o de las cooperativas y lo que hace el Programa de Paz y Desarrollo del Magdalena Medio, que si bien es discutible, no se puede demeritar con la sola frase de que "es financiado por el Banco Mundial” (pág. 188), sobre todo, cuando su origen fue un acuerdo entre

3 * Me refiero al texto Violencia contra el sindicalismo, 1984-2010, Bogotá, Cinep, 2012. 
el clero, la USO y Ecopetrol, y fue orientado por el carismático sacerdote jesuita Francisco De Roux, a quien la autora nunca menciona.

En este punto es necesario reiterar que el argumento de Lesley Gill es coherentemente construido y contiene mucha evidencia empírica como para desconocerlo. Pero el enfoque teórico y político de clase, la hace caer en ese pesimismo muy propio de una lectura estructural que no percibe los matices de resistencia cotidiana de la gente, quienes no destruyen el orden autoritario, pero no lo aceptan integralmente y nunca se someten del todo. Ese mismo enfoque la conduce a una dura crítica del lenguaje de derechos humanos, así la misma autora reconozca que fue la única alternativa viable de resistir en un contexto de dura violencia paramilitar. Y es bueno aclarar que ella es crítica también de la violencia guerrillera, no la idealiza ni la oculta, pero sí le reconoce los lazos que en algunos momentos pudo tener con la población civil. Y por esa vía toma distancia también de la cultura de izquierda incluyendo a los sindicalistas, que aún en el presente siguen siendo homofóbicos y poco favorables a cambios en asuntos de género y diversidad sexual.

En cuanto a la forma, el libro se lee con agrado a pesar de su duro contenido. Como ya dijimos, la autora hace un acertado uso de los testimonios para narrar eventos traumáticos que de otra forma serían difíciles de comunicar. Pero a veces, dentro de los capítulos, hay una forma circular de argumentar con reiteraciones sobre temas no siempre claramente organizados. Existen también algunos errores puntuales de nombres y fechas, que seguramente son descuidos de digitación. En cambio hay un problema más serio al dar cifras exageradas sobre la violencia contra los trabajadores como en la página 116 en la que, sin citar la fuente, se afirma que entre 1986 y 2003 fueron asesinados 4.000 sindicalistas de la CUT — la central obrera más grande mas no la única-, cuando analistas de la Escuela Nacional Sindical y nuestras propias pesquisas arrojan una cifra cercana a 3.000 asesinados para el conjunto del sindicalismo entre 1984 y 2010. Pero estos errores no demeritan la calidad académica del libro y sus aportes, que son principalmente etno- 
gráficos y de denuncia. En efecto, el conjunto del libro es una lectura coherente de las indudables transformaciones del mundo del trabajo en Barranca y en el país, como en el conjunto del planeta, que arrojan valiosas lecciones, entre otras, sobre el compromiso de los intelectuales con las causas populares.

Concluyo reconociendo el valor académico y ético del libro de Lesley Gill, y señalo que, paradójicamente, aunque la autora no menciona los diálogos de paz con la insurgencia que se hicieron públicos desde 2012 - algo que tal vez hubiera matizado su pesimismo-, este libro hace más necesarios que nunca estos acuerdos para que ese mundo de terror, inseguridad y desconfianza, que tan bien describe y analiza, no se repita. 